\title{
Around the World in 80 Plants: An Edible Perennial Vegetable Adventure in Temperate Climates. By Stephen Barstow. 2014. Permanent Publications, East Meon. 304 pp.
}

\author{
Ada Grabowska-Zhang ${ }^{1^{*}}$ \\ ${ }^{1}$ Department of Zoology, University of Oxford, South Parks Road, Oxford, OX1 3PS, UK. \\ *ada.grabowska@zoo.ox.ac.uk \\ Received September 25, 2015 \\ OPEN ӘACCESS \\ Accepted January 8, 2016 \\ DOI 10.14237/ebl.7.1.2016.492 \\ Copyright (C) 2016 Grabowska-Zhang; licensee Society of Ethnobiology. This is an open-access article distributed under the terms of the Creative Commons \\ Attribution-NonCommercial 4.0 International Public License (https://creativecommons.org/licenses/by-nc/4.0), which permits non-commercial use, distribution, \\ and reproduction in any medium, provided the original author and source are credited.
}

I hope you like garlic.

For the community of sustainability-minded gardeners and permaculture enthusiasts this was the most anticipated publication of the year 2014. This fascinating catalogue of useful plants has roots in the author's personal story. A native of the British Isles, thirty years ago Stephen Barstow found himself in a far flung corner of Norway, where he could find precious little to satisfy his vegetarian diet. And so his quest for useful, tasty, perennial plants that would thrive in cool climates began.

In 284 pages, Stephen Barstow takes us on a thrilling, mouth-watering voyage through the continents, focusing on perennial leafy vegetables and "edimentals" - a term he uses for edible plants that wouldn't be out of place in an ornamental garden. But the book is not a field-guide, gardening manual, or a cookbook; instead it strikes a pleasing balance of information, storytelling, and serious academic referencing, peppered with the occasional traditional recipe. The reader is introduced to interesting specimens, such as the altitude-sickness-curing garlic of the Sherpas (Allium wallichii), and the plant that protects the Māori from cancer (sow-thistle, Sonchus spp.). There are plenty of examples of historical and current cultural practices for nearly all of plants described. Barstow's careful attention to citing his sources makes this book a useful reference to inspire further research, especially if you are interested in the ethnobotany of Allium. This genus features in the book quite prominently, comprising nearly a quarter of the species described. This is exciting for me, but perhaps not everyone's cup of tea.
The book is, refreshingly, tailored for the cool climate gardener. Alys Fowler (p. xi) rightly points out in the foreword: "If he can grow it; so can you." However, Barstow's plants are not cold specialists, and many species he describes have wide geographical ranges, so even gardeners in Mediterranean-type climates can pick up new additions to their diet. More importantly, by focusing on perennial plants, this book opens up options for those unwilling or unable to take on the intensity of annual vegetable growing. There is definitely a place for this type of publication in promoting a varied diet and sustainable home food production. Sure, this volume might only reach adventurous gardeners, and perhaps their dinner guests. But all change has to start somewhere. And it is a good start, because the recipes may only come from the next town over, or a generation away, and thus perhaps still familiar to industrialized inhabitants of Europe and North America. Barstow's contagious enthusiasm, conveyed through his descriptions, stories, and historical accounts, made me fling the book aside in mid-sentence and rummage through my cupboards for a muslin cloth to make dock pudding (p. 262), before realizing it would be another ten months before the ingredients are in season again.

The book most prominently features European plants from various regions that yield three separate chapters. Two chapters cover Asia and Australia, and one chapter focuses on the Americas. Surprisingly, Africa was omitted altogether. This is so surprising because cold tolerant African vegetables have been grown in temperate climates, such as members of the Amaranthaceae family. However, Barstow clearly 
states that the book covers eighty of his favorite vegetables, a small sample of the great collection he curates and writes about on his website (Edimentals 2016).

My only reservation with this book is that cultural references are sometimes clumsily handled in a way that might offend readers. I was a little taken aback by references to 'Eskimos' outside of historical quotes. That is something that should at least have been picked up by the editor. Otherwise the book is nicely published, with informative, and sometimes beautiful, photographs on every page.

And yes, plenty of garlic.

\section{References Cited}

Edimentals. 2016. Available at: http:/ / www.edimentals.com/blog/. Accessed on: February 6, 2016. 